Pierpaolo Lunardi

Michele Acqui

Giovanna Ricci

Antonino Agrillo

Luigi Ferrante

\section{Cervical synovial cysts: case report and review of the literature}

Received: 12 January 1998

Revised: 17 September 1998

Accepted: 19 October 1998

P. Lunardi - M. Acqui - G. Ricci

A. Agrillo $\cdot$ L. Ferrante

Department of Neurological Sciences,

"La Sapienza" University of Rome,

Rome, Italy

M. Acqui ( $\square)$

Neurochirurgia, Viale dell'Università 30a, I-00185 Rome, Italy

\begin{abstract}
The authors describe the case of a 58-year-old man with a 6month history of severe myelopathy. CT scan and MRI of the spine revealed a cystic formation, measuring about $1 \mathrm{~cm}$ in diameter, at C7-T1 at a right posterolateral site at the level of the articular facet. At operation the mass appeared to originate from the ligamentum flavum at the level of the articular facet and was in contact with the dura mater. Once the mass had been removed, there was a significant amelioration of the patient's symptoms. As previously suspected, histological aspect was synovial cyst. Cervical synovial cysts are extremely rare and, as far as we know, only 22 cases have so far been described in the literature. Diagnos-
\end{abstract}

tic radiological investigations used were CT scan and MRI. At CT scan the most important diagnostic findings are a posterolateral juxtafacet location of the mass, egg-shell calcifications on the wall of the cyst, and air inside the cyst. At MRI the contents of the cyst are iso/hypointense on T1- and hyperintense on T2weighted images. There may also be a hypointense rim on T2-weighted images, which enhances after i.v. administration of gadolinium. Surgical treatment consists of removal of the mass. Fixation of the vertebral segments involved is not always necessary.

Key words Synovial cyst $\cdot \mathrm{CT}$. MRI · Surgical treatment

\section{Introduction}

Synovial cysts are cystic dilatations of the synovial sheaths; they are bordered not only by the connectival tissue structures of these sheaths but also by the mono- or pluri-stratified cuboid synovial epithelium. Anatomical continuity with the synovial sheaths of the joint cavities from which the cyst probably originates may not always be observed.

While synovial cysts are quite a frequent occurrence in joints and tendon sheaths $[3,10,23]$, especially in the joints of the hands and wrists [45], they are very rare in the spine $[13,18,25,40,47,62]$. In the lumbar spine 220 cases have been described $[1,2,16,21,28,34,38$, $40,43,45,48,51,54-56,60]$.

The incidence of synovial cysts with a cervical location was evaluated, with reference to veterinary literature too [15], and was found to be an occurrence specific to humans, of which, to our knowledge, only 22 cases have been reported to date.

We describe another case of cervical synovial cyst and discuss the pathological, etiopathogenetic, and clinical aspects of this rare pathology.

\section{Case report}

A 58-year-old man was referred to us with a progressive spastic paraparesis, which had started 8 months earlier. About 2 months prior to admission, he had begun to suffer from genital-sphincteric ailments such as urinary retention and difficult erection.

Examination revealed a severe motor deficit in the lower limbs (he was able to raise his legs while lying in bed for a few seconds only), as well as an increased response to knee and ankle jerks. There was superficial and deep hypoesthesia below C8 and apallesthesia below the iliac crests. There was also urinary retention, which required catheterization. 

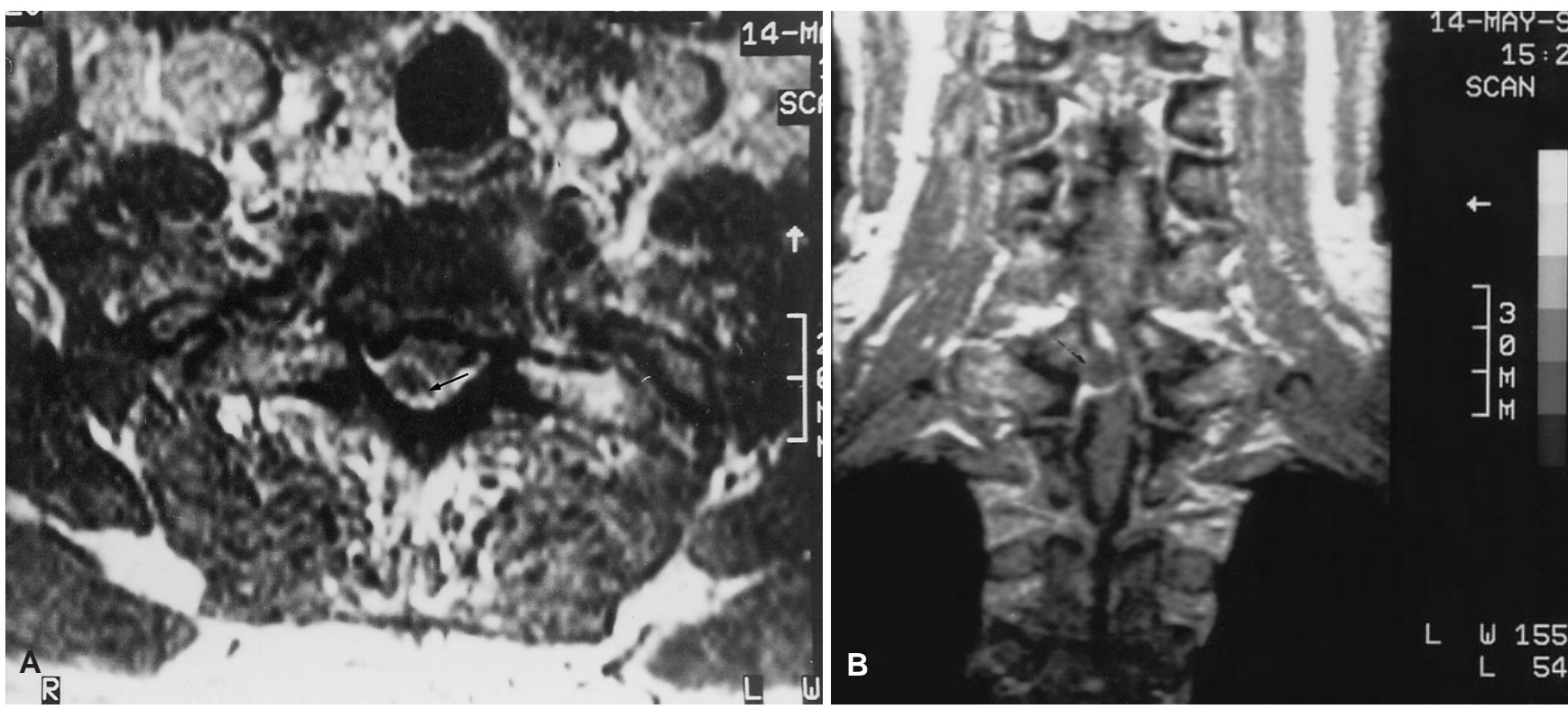

Fig. 1 A Axial and $\mathbf{B}$ coronal MR images showing an expansive lesion located posterolaterally to the right of the spinal cord at the level of the interlaminar space of C7-T1, with marked compression of the neuraxial structures, hypointense with respect to the spinal parenchyma on T1-weighted images, with peripheral signal enhancement after i.v. administration of gadolinium

A CT scan of the cervical spine identified a hypodense cystic formation with a hyperdense rim, located in a right posterolateral position with respect to the spinal cord, behind the right joint facet at C7-T1 level.

Cervical MRI with axial (Fig. 1 A) and coronal (Fig. 1 B) views revealed not only spondylosis of the vertebral bodies and narrowing of the perimedullary subarachnoid spaces, but also a mass located posterolaterally to the right of the spinal cord at the C7-T1 level with marked compression of the neuraxial structures. The central portion of this formation was hypointense in relation to the spinal parenchyma on T1-weighted images, with a peripheral signal increase following i.v. administration of gadolinium.

Surgery

The laminae of C7 and T1 were removed. At the level of the right articular facet and below the ligamentum flavum there was a cyst, measuring about $1.5 \mathrm{~cm}$, which adhered to the dural surface but was easily separated from it, like "the peel from a peach".

In the first few days after surgery there was an initial but evident improvement in motility of the lower limb, which enabled the patient to take a few steps while supported. Six months after surgery, neurological improvement was such that he could walk unaided and the superficial and deep hypoesthesia had regressed. He had also regained control of bowel and bladder function as well as sexual activity.

\section{Review of the literature}

The 14 cases of cervical synovial cyst culled from the literature and the present case are presented in Table 1.
To these we can add the four cases mentioned by Sabo et al., but not described in detail [48], in the context of a review of a personal series of synovial cysts. No information other than the level of the cyst was mentioned in 3 of the 4 cases: C4-C5 in two cases and C7$\mathrm{T} 1$ in one. We can also add the three cases described by Houser et al. [27], which were part of a clinical-radiological review of cervical foraminal stenoses, likewise not described in detail.

There were ten men and four women (in the case described by Freidberg et al. [17] the sex of the patient was not mentioned), with an average age of 62.2 years (range 41-82 years). The level of the cyst was the atlanto-axial junction in six cases, C7-T1 in four, C6-C7 and C4-C5 in two cases each, and $\mathrm{C} 3-\mathrm{C} 4$ in one case.

In 11 cases the lesion caused myelopathy, in 2 radiculopathy and in 2 myelo-radiculopathy. In all seven cases in which myelography was performed, a block of contrast medium was revealed in the spinal subarachnoid space due to the presence of the mass. In all nine cases in which CT or myelo-CT was performed, the scans demonstrated the presence of the cyst. In one case [42] there was an "egg-shell" parietal calcification, while in another a hypodense area was visualized within the cyst, attributable to air inside it.

MRI was carried out in nine cases; in all of them it identified the lesion, which was hypo/isointense on T1weighted images in seven cases $[9,14,20,41,55,59$, our case], hyperintense on T2-weighted images in five cases $[14,17,20,55,59]$ and hypointense on T2-weighted images in one case [9]. In one case the lesion was hyperintense on T2-weighted images with a hypodense rim [59]. Two cases $[9,59]$ displayed enhancement of the cyst wall.

All patients were treated surgically and the lesion was always removed. Surgical outcome was good in all cases 
Table 1 Details of 14 cases of cervical synovial cysts reported in the literature plus the present case

\begin{tabular}{|c|c|c|c|c|c|}
\hline Author, year & $\begin{array}{l}\text { Age, } \\
\operatorname{sex}\end{array}$ & Spinal level & Clinical signs & Radiology & Follow-up \\
\hline Kao et al. (1974) [31] & $52, \mathrm{M}$ & C6-C7 & Radiculopathy & Myelography & 3 months: well \\
\hline Cartwright et al. (1985) [8] & $41, \mathrm{M}$ & C7-T1 & Myelopathy & Myelography, CT & 1 year: well \\
\hline Jabre et al. (1987) [29] & $60, \mathrm{M}$ & C6-C7 & Myelopathy & Myelography & 4 months: well \\
\hline Onofrio and Mih (1988) [43] & $73, \mathrm{M}$ & $\begin{array}{l}\text { Atlanto-axial } \\
\text { junct. }\end{array}$ & Myelopathy & CT & 4 years: well \\
\hline Patel and Sanders (1988) [44] & $42, \mathrm{~F}$ & $\mathrm{C} 4-\mathrm{C} 5$ & Radiculopathy & Stratigraphy & \\
\hline Miller et al. (1989) [41] & $67, \mathrm{~F}$ & $\mathrm{C} 1-\mathrm{C} 2$ & Myelopathy & $\begin{array}{l}\text { Myelography, CT, Angio- } \\
\text { graphy, MRI }\end{array}$ & Improved \\
\hline Nijensohn et al. (1990) [42] & $58, \mathrm{M}$ & $\mathrm{C} 4-\mathrm{C} 5$ & Myelo-radiculopathy & X-ray, Myelo-CT, MRI & Improved \\
\hline Quaghebeur and Jeffree (1992) [46] & $82, \mathrm{~F}$ & $\mathrm{C} 1-\mathrm{C} 2$ & Myelopathy & Myelography, Myelo-CT & 1 year: well \\
\hline Takano et al. (1992) [55] & $72, \mathrm{M}$ & $\mathrm{C} 3-\mathrm{C} 4$ & Myelopathy & Myelography, Myelo-CT, MRI & Perfect \\
\hline Goffin et al. (1992) [20] & $65, \mathrm{M}$ & $\begin{array}{l}\text { Atlanto-axial } \\
\text { junct. }\end{array}$ & Myelopathy & Myelography, Myelo-CT, MRI & Improved \\
\hline Choe et al. (1993) [9] & $61, \mathrm{M}$ & $\begin{array}{l}\text { Atlanto-axial } \\
\text { junct. }\end{array}$ & Myelopathy & MRI & Improved \\
\hline Epstein and Hollingsworth (1993) [14] & $47, \mathrm{M}$ & C7-T1 & Myelo-radiculopathy & MRI & Improved \\
\hline Weymann et al. (1993) [59] & $72, \mathrm{~F}$ & $\mathrm{C} 1-\mathrm{C} 2$ & Myelopathy & CT, MRI & Improved \\
\hline Freidberg et al. (1994) [17] & - & C7-T1 & Myelopathy & MRI & 5 years: perfect \\
\hline Present case & $58, \mathrm{M}$ & C7-T1 & Myelopathy & CT, MRI & Improved \\
\hline
\end{tabular}

(with the exception of the one reported by Patel and Sanders [44], in which no follow-up data are supplied).

\section{Discussion}

The first reported case of spinal synovial cyst was diagnosed at autopsy by Von Gruker in 1880 (cited without a reference by Pendleton et al. [45]), while the first clinical case was described in 1950 by Vosschulte and Borger [58] in a patient with radicular spinal compression secondary to a synovial cyst.

The rarity of this pathology is confirmed by the clinical and radiological series reported by Zoch [62] and Mercader et al. [40]. The former, in the pre-CT era, identified only one case of lumbar synovial cyst out of 8487 operations for disc herniation or spinal tumor, while the latter reviewed 1500 lumbar-sacral CT scans and discovered only three cases.

From an anatomo-pathological viewpoint, the gross appearance of spinal synovial cyst resembles an extradural cystic formation about the size of a pea or a nut, situated posterolateral to the dural sac at the level of the ventral aspect of the articular facets $[2,30]$. On occasion, it may be located on the dorsal aspect of the facets and extend into the soft paravertebral tissues; in this event there are either no symptoms [31, 45] or just low-back pain [2, 40]. In one case the cyst is described as developing entirely within the ligamentum flavum, dissecting the fibers inside it [16].

Some authors have adopted the single term "juxtafacet cyst" to describe both of the two distinct nosographic types [16, 32, 45, 48], namely true synovial cysts and ganglion cysts. In our opinion these two types of cyst differ both anatomo-pathologically and etiopathogenetically. Their anatomo-pathological differences regard gross appearance and histological aspect of the capsule. Macroscopically, their external appearance is similar, but ganglion cysts contain a sticky or gelatinous protein material whereas synovial cysts contain clear or xanthochromic fluid [16, 32, 48]. Histologically, the principal discriminating aspect, in addition to the connective tissue composition of the capsule (consisting of collagen in ganglion cysts and lax hyperplastic vascularized connective tissue, occasionally with signs of phlogosis, in synovial cysts [16]), is the presence of mono- or pluri-stratified cuboid epithelium, hyperplastic in some cases, which is only present in the synovial type $[16,32,33,54]$. Their pathogenetic differences lie in the fact that ganglion cysts are thought to derive from mucoid degeneration of the periarticular fibrous adventitial tissue, excess production of hyaluronic acid by the fibroblasts, and proliferation of the pluripotent mesenchymal cells $[16,54]$, whereas synovial cysts seem to originate from herniation of the synovial membrane across the articular capsule of the facet [16].

Although this classification is accepted by some authors, it is challenged by Amour et al. [2], who affirm that the most important discriminating aspects, such as the presence of synovial epithelium and communication with the articular space, may not be present because regressive phenomena of the epithelium secondary to chronic inflammation may lead to obliteration of the connection with the articular space. Moreover, in a case described by 
Hsu et al. [28], the histological characteristics of both synovial and ganglion cyst were observed. Thus it seems that, in the majority of cases, the distinction between ganglion and synovial cysts is not so much real as semantic $[2,30]$. In fact, Sabo et al. affirm that "there is no clinical significance in distinguishing between the ganglion and synovial cyst because their treatment and prognosis are the same" [48].

Savitz [49, 50] classifies synovial cysts, ganglion cysts, hypertrophic synovitis, and villonodular synovitis all together. However, many authors deny the existence of the last two conditions $[6,19,39,57]$. It seems likely that only hypertrophic synovitis could represent an initial stage of synovial or ganglion cyst, in view of its frequent association with degenerative and arthrotic processes.

The etiology of synovial cyst is controversial and several factors are thought to play a role in their origin. These are principally degenerative, traumatic, congenital and inflammatory. Most patients with synovial cysts simultaneously present signs of spondylodiscarthrosis [2] and hypermobility of a spinal segment, secondary to dehydration of the intervertebral disc. This leads to progressive weakening of the capsules of the joint facets, which may either result in degenerative spondylolisthesis, present in $67 \%$ of patients with lumbar synovial cysts [43], or favor onset of the cyst itself [26]. In fact, in about $70 \%$ of cases it involves the facet joints of L4-L5, the most mobile segment of the spine [7, 40].

As regards the pathological modifications of the ligamentum flavum during spondylodiscarthrosis, Abdullah et al. [1] sustain that they may lead to cyst formation (classified by the authors as synovial cysts of the ligamentum flavum) by means of mucoid or hyalin degeneration of the fibers with consequent necrosis, fibrosis, calcification, and cyst formation with endothelial proliferation in the degenerated areas. In the case reported by Takano ert al. [55], the cyst was situated entirely within the ligamentum flavum at $\mathrm{C} 3-\mathrm{C} 4$ level. Among the cases reviewed, Takano ert al. were the only authors to describe this finding, which was identical to our own observation in that surgical inspection revealed an intraligamental synovial cyst at C7-T1 with no apparent involvement of the articular facets. In addition, there were marked signs of cervical spondyloarthrosis. These aspects seem to support the hypothesis that spondyloarthrotic degeneration plays a important role in the pathogenesis of synovial cysts.

The traumatic etiology of these cysts is not universally accepted, principally because in many cases the interval between trauma and clinical onset was very long [2, 8, 54]. However, a traumatic etiology seems very likely in the case reported by Franck et al. [16], because there was a concomitant post-traumatic diastasis of the interapophyseal joint from which the synovial cyst originated. Moreover, the frequent observation of hemorrhagic residues $[2,5$, $16,45,54]$ and calcifications [2, 54] makes this etiology likely in some cases.

As far as congenital etiology is concerned, some authors believe that spinal synovial cysts are generated by synovial tissue included with the periarticular fibro-connective tissue [4, 23, 35, 39, 45].

Lastly, rare cases of synovial cysts during rheumatoid arthritis have been reported [36].

Nowadays, diagnosis of spinal synovial cyst relies on CT scan and MRI. CT elements diagnostic for spinal synovial cyst are considered to be not only a circular formation in the medial portion and a posterolateral location with respect to the spinal cord, but also a roundish calcification of the cyst wall $[2,28,33,40]$ - probably the consequence of previous degenerative-hemorrhagic or inflammatory processes - and the presence of air within the cyst $[28,33,40,52,53]$, probably deriving from the degenerated articular facets by an "ex vacuo" process $[28$, 52].

MRI was performed in eight cases. Similarly to the more common lumbar synovial cysts $[12,30,61]$, the lesion manifests as a well-defined roundish formation, in close contact with the interapophyseal joints, iso/hypointense on T1- and hyperintense on T2-weighted images with respect to cerebrospinal fluid [2]. The different signal modulations possible are due to the variable consistency and density of the cystic fluid, which ranges from serous through proteinous to hemorrhagic $[2,7]$. A hypointense ring, better visible on T2-weighting, is described, which presents enhancement after i.v. administration of gadolinium $[9,33]$ and is attributed to chronic perilesional inflammation [51, 61] or calcification of the wall [28]. Sometimes a connection between the cyst and the articular space was identified, with enhancement of the corresponding articular extremities [61].

Differential diagnosis of extradural spinal cyst must include a detached disc fragment, extradural metastasis, meningioma, schwannoma, cystic neurofibroma, dermoid cyst, parasitary cyst, perineural cyst, extradural arachnoid cyst, hypertrophic synovitis, and hypertrophic pigmented villonodular synovitis [11, 16, 32].

Some authors report a reduction of spinal synovial cysts with conservative treatment or minor surgery. The former consists of bed-rest, analgesic drugs and orthosis $[22,28,40]$, while the latter consists of CT-guided aspiration of the cyst contents plus epidural or intra-articular injection of cortisone [28]. While these therapeutic methods may play a role in lumbar synovial cysts, which mainly give radicular symptoms (as long as the diagnosis is certain), in our view they are not appropriate in patients with cervical cysts, who usually present with severe myelopathy. 


\section{References}

1. Abdullah AF, Chambers RW, Daut DP (1984) Lumbar nerve root compression by synovial cysts of the ligamentum flavum. J Neurosurg 60: 617620

2. Amour TES (1994) Synovial cyst. In: Amour TES, Hodges S, Laakman RW, Tamas DE (eds) MRI of the spine. Raven Press, New York, pp 120-125

3. Bennet GA (1950) Reactive and neoplastic changes in synovial tissue (Richard Hermann Jaffé memorial lecture). Proc Inst Med Chicago 18: 2637

4. Bhushan C, Hodges FJ III, Wityk JJ (1979) Synovial cyst (ganglion) of the lumbar spine simulating extradural mass. Neuroradiology 18: 263-268

5. Brish A, Payan HM (1972) Lumbar intraspinal extradural ganglion cyst. J Neurol Neurosurg Psychiatry 35: 771-775

6. Bullough PG (1992) Pigmented villonodular synovitis and synovial cyst of the spine. AJNR 13: 167-168

7. Cameron SE, Hanscom DA (1992) Rapid development of a spinal synovial cyst. A case report. Spine 17: $1528-1530$

8. Cartwright MJ, Nehls DG, Carrion CA, Spetzler RF (1985) Synovial cyst of a cervical facet joint: case report. Neurosurgery 16: 850-852

9. Choe W, Walot I, Schlesinger C, Chambi I, Lin F (1993) Synovial cyst of the dens causing spinal cord compression. Case report. Paraplegia 31: 803-807

10. Cloward RB, Bucy PC (1937) Spinal extradural cyst and kyphosis dorsalis juvenilis. AJR 38: 681-706

11. Cloward RB (1968) Congenital spinal extradural cyst: case report and review of literature. Ann Surg 168: 851-864

12. Davis R, Iliya A, Roque C, Pampati M (1990) The advantage of magnetic resonance imaging of a lumbar synovial cyst. Spine 15: 244-246

13. Doherty PF, Sherman BA, Stein C, White R (1993) Bilateral synovial cyst of the thoracic spine: a case report. Surg Neurol 39: 279-281

14. Epstein NE, Hollingsworth R (1993) Synovial cyst of the cervical spine. J Spinal Disord 6: 182-185

15. Fisher LF, Bowman KF, MacHarg MA (1983) Spinal ataxia in a horse caused by a synovial cyst. Vet Pathol 18: 407410

16. Franck JI, King RB, Petro GR, Kanzer MD (1987) A posttraumatic lumbar synovial cyst. J Neurosurg 66: 293-296
17. Freidberg SR, Fellow T, Thomas CB Mancall AC (1994) Experience with symptomatic spinal epidural cyst. Neurosurgery 34: 989-993

18. Fritz RC, Kaiser JA, White AH, Delong WB, Gamburd RS (1994) Magnetic resonance imaging of a thoracic intraspinal synovial cyst. Spine 19: 487-490

19. Giannini C, Scheithauer BW (1996) Villonodular synovitis (letter). J Neurosurg 85: 528

20. Goffin J, Wilms G, Plets C, Bruneel B, Casselman J (1992) Synovial cyst at the C1-C2 junction. Neurosurgery 30 : 914-916

21. Gomez-Vaquero C, Valverde J, Fiter J, Sanchez-Laforga A (1995) Lumbar intraspinal juxtaarticular cyst. Report of a case with MRI findings (letter). Rev Rhum Engl Ed 62: 55-56

22. Hemminghytt S, Daniels DL, Williams AL, Haughton VM (1982) Intraspinal synovial cyst: natural history and diagnosis by CT. Radiology 145: 375-376

23. Herrington JL Jr, Edwards LW (1955) Ganglion cyst arising in unusual locations. Ann Surg 142: 900-903

24. Deleted

25. Hodges SD, Fronczak S, Zindrick MR, Lorenz MA, Vrbos LA (1994) Extradural synovial thoracic cyst. Spine 19: $2471-2473$

26. Holtzman RN, Dubin RR, Yang WC, Rorat E, Liu HM, Leeds NE (1987) Bi lateral symptomatic intraspinal T12-L1 synovial cyst. Surg Neurol 28: 225 230

27. Houser OW, Onofrio BM, Miller GM, Folger WN, Smith PL, Kallman DA (1993) Cervical neural foraminal canal stenosis: computerized tomographic myelography diagnosis. J Neurosurg 79: 84-88

28. Hsu KY, Zucherman JF, Shea WJ, Jeffry RA (1995) Lumbar intraspinal synovial and ganglion cyst (facet cysts). Ten-year experience in evaluation and treatment. Spine 20: 80-89

29. Jabre A, Shahbabian S, Keller JT (1987) Synovial cyst of the cervical spine. Neurosurgery 20: 316-318

30. Jackson DE, Atlas SW, Mani JR, Norman D (1989) Intraspinal synovial cyst: MR imaging. Radiology 170: 527-530

31. Kao CC, Uihlein A, Bickel WH, Soule EH (1968) Lumbar intraspinal extradural ganglion cyst. J Neurosurg 29: 168-172

32. Kao CC, Winkler SS, Turner JH (1974) Synovial cyst of spinal facet. J Neurosurg 41: 372-376
33. Khoury GM, Shimkin PM, Kleinman GM, Mastroianni PP, Nijenshon DE (1991) Computed tomography and magnetic resonance imaging findings of pigmented villonodular synovitis of the spine. Spine 16: 1236-1237

34. Kornberg M (1995) Nerve root compression by a ganglion cyst of the lumber anulus fibrosus. A case report. Spine 20: 1633-1635

35. Kurz LT, Garfin SR, Unger AS, Thorne RP, Rothman RH (1985) Intraspinal synovial cyst causing sciatica. J Bone Joint Surg [Am] 67: 865-871

36. Linquist PR, McDonnel DE (1970) Rheumatoid cyst causing extradural compression. A case report. J Bone Joint Surg [Am] 52: 1235-1240

37. Liu SS, Williams KD, Drayer BP, Spetzler RF, Sonntag VKH (1990) Synovial cyst of the lumbosacral spine: diagnosis by MR imaging. AJNR 10: 1239-1242

38. Marion PJ, Kahanovitz N (1995) Lumbar-sacral radiculopathy secondary to intraspinal synovial cyst. Arch Phys Med Rehabil 76: 1011-1013

39. McCormic PW (1994) Pigmented villonodular synovitis (letter). J Neurosurg 80: 957-958

40. Mercader J, Munoz Gomez J, Cardenal C (1985) Intraspinal synovial cyst: diagnosis by CT. Neuroradiology 27 : 346-348

41. Miller JD, Al-Mefty O, Middleton TH (1989) Synovial cyst at the craniovertebral junction. Surg Neurol 31: 239-242

42. Nijensohn E, Russel EJ, Milan M, Brown T (1990) Calcified synovial cyst of the cervical spine: CT and MR evaluation. J Comput Assist Tomogr 14: 473-476

43. Onofrio B, Mih AD (1988) Synovial cyst of the spine. Neurosurgery 22: 642-647

44. Patel SC, Sanders WP (1988) Synovial cyst of the cervical spine: case report and review of the literature. AJNR 9: 602-603

45. Pendleton B, Carl B, Pollay M (1983) Spinal extradural benign synovial or ganglion cyst: case report and review of the literature. Neurosurgery 13 : 322-326

46. Quaghebeur G, Jeffree M (1992) Synovial cyst of the high cervical spine causing myelopathy. AJNR 13: 981982

47. Rapin PA, Gester JC (1993) Calcified synovial cyst of a zygoapophyseal joint (letter). J Rheumatol 20: 767-768 
48. Sabo AR, Tracy PT, Weinger LM (1996) A series of 60 juxtafacet cysts: clinical presentation, the role of spinal instability, and treatment. J Neurosurg 85: 560-565

49. Savitz MH (1994) Pigmented villonodular synovitis (letter). J Neurosurg 80: 956-957

50. Savitz MH (1996) Villonodular synovitis (letter). J Neurosurg 85: 527-528

51. Silbergleit R, Gebarski SS, Brumberg JA, McGillicudy J, Blaivas M (1990) Lumbar synovial cyst: AJNR 11: 777-779

52. Spencer RR, Jahnke RW, Hardy LH (1983) Dissection of gas into an intraspinal synovial cyst from contiguous vacuum facet. J Comput Assist Tomogr 7: $886-888$
53. Steinberg ML, Rose WS, Ruchman RB (1995) Case report: intraspinal synovial cyst containing gas. N J Med 92: 169-171

54. Sypert GW, Leech RW, Harris AB (1973) Posttraumatic lumbar epidural true synovial cyst. Case report. J Neurosurg 39: 246-248

55. Takano Y, Homma T, Okumura H, Takahashi HE (1992) Ganglion cyst occurring in the ligamentum flavum of the cervical spine. Spine 17: 15311533

56. Tatter SB, Cosgrove GR (1994) Hemorrhage into a lumbar synovial cyst causing an acute cauda equina syndrome. Case report. J Neurosurg 81: 449-452

57. Unni KK (1996) Pigmented villonodular synovitis (letter). J Neurosurg 80: 958

58. Vosschulte K, Borger G (1950) Anatomische und funktionelle Untersuchungen über den Bandscheibenprolaps. Langenbecks Arch Klin Chir 265: S329-355
59. Weymann CA, Capone P, Kinkel PR, Kinkel WR (1993) Synovial cyst of the upper cervical spine: MRI with gadolinium. Neurology 43: 2151-2152

60. Yarde WL, Arnold PM, Kepes JJ, O'Boynick PL, Wilkinson SB, Batnitzky S (1995) Synovial cyst of the lumbar spine: diagnosis, surgical management and pathogenesis. Report of eight cases. Surg Neurol 43: 459-464

61. Yuh WTC, Drew JM, Weinstein JN, McGuire CW, Moore TE, Kathol MH, El-Khoury GY (1991) Intraspinal synovial cyst. Magnetic resonance evaluation. Spine 16: 740-745

62.Zoch VK (1969) Über ein vertebrales Gelenksganglion mit den Symptomen der intraspinalen Raumforderung. Schweiz Arch Neurol Neurochir Psychiatr 105: 323-327 